\title{
Integrating Psychotherapy and Occupational Counselling in Family Projects: An Action Theoretical View
}

\section{Valach Ladislav}

Private practice, Lindenstrasse 26, 3047 Bremgarten, Switzerland

Corresponding Author: Valach, Ladislav, H Private practice, Lindenstrasse 26, 3047 Bremgarten, Switzerland.

E-mail: ladislav.valach@swissonline.ch

Received date: December 20, 2018;Accepted date : January 16, 2019; Published date: January 18, 2019.

Citation : Valach Ladislav, Integrating Psychotherapy and Occupational Counselling in Family Projects: An Action Theoretical View, J. Psychology and Mental Health Care . Doi: 10.31579/ 2637-8892.19/009.

Copyright : @2019ValachLadislav. This is anopen-access articledistributed under the terms of TheCreativeCommons Attribution License, whichpermits unrestricted use, distribution, and reproduction in any medium, provided the original author and source are credited.

\section{Abstract}

The current career understanding develops away from institutionally outlined career track to informal personal and socially shared career conceptualization. Richardson (2002, 1993) suggested that occupational counselling and psychotherapy should become more integrated and thus better address this issue. We propose that we need a new conceptualization which would see career and occupational projects as being constructed in the personal and social processes and could provide a new basis for counselling integrating occupational counselling, psychotherapy and dealing with joint processes on a basis common to all three views. The core of this conceptualization is the idea of goal-directed system processes organized in action, projects and career, which are related to a number of issues such as occupational career, but also mental and physical health and relationships (Domene, Valach, \& Young, 2015; Valach, Young, \& Lynam, 2002; Young, Valach, \& Collin, 2002).

This conceptualization will be outlined, several cases will be described in which the intertwining of various issues asking for occupational, therapeutical and family related intervention is visible and, finally, a brief quantitative and qualitative overview will be provided of the occurrence of the occupational, life and suicide related joint issues in 40 interviews with patients after a non-fatal suicide action (Valach, Young, \& Michel, 1997).

Keywords: integrating psychotherapy; occupational counselling; family projects; conceptualization

Integrating psychotherapy and occupational counselling in family projects: An action theoretical view

The current development in career understanding indicates a trend away from institutionally outlined, marked and provided career track to informal personal and socially shared career conceptualization (Savickas, 2005; Young, \& Collin, 2000, Young, \& Valach, 2000). That is, while there still might be some institutionally and organizationally carried career trajectories, there is a recognizable shift to mainly socially shared representation of a career serving as a lead to understanding and organizing occupational actions and projects in a particular society without being determined by the organizational environment. This is linked to internalization of such patterns, which become steering cognitions in personal and occupation related joint actions and projects. Consequently, the career patterns of occupational life become less a socio-economical -organizational issue attached to specific bureaucracies or enterprises, but a more personal and social matter. As such, it relies on personal and social construction processes (Young, \& Valach, 2004) and, therefore, it also is more vulnerable to personal and social complications. It has recently been suggested that occupational counselling and psychotherapy should become more integrated (Richardson, 1993, 2002) with the feeling that the, above described issues could be better addressed in such a merge. However, it has also been indicated that processes related to occupational issue are mostly relational or joint processes (Young, 1984) and that family, mostly family of origin substantially influences these processes (Whiston \& Keller, 2004). Young, Valach and colleagues (2002) suggested that career and occupation are not just influenced by family structure and family processes, but that some of the most important family projects are related to occupational issues (Young et al. 2000).
The bottom line of this argumentation is that in such a new situation we need a new conceptualization, which would allow integrating these issues of career and occupational projects being constructed in the personal and social processes and not exclusively in organization structures. This could provide a new basis for counselling which would integrate occupational counselling, psychotherapy and dealing with joint processes on the basis common to all three views.

The present contribution will briefly address the conceptual outline of this approach and provide a brief qualitative overview of the occurrence of the occupational, life and suicide related joint issues and family projects in 40 interviews with patients after a non-lethal suicide action.

\section{Conceptual outline of the action theoretically informed approach}

The core of this conceptualization is the idea of goal-directed system processes organized in action, projects and career, which are related to a number of issues such as occupational career, but also mental and physical health and relationships (Domene, Valach, \& Young, 2015; Valach, \& Young, 2004; Valach, Young, \& Lynam, 2002; Young, Valach, \& Collin, 2000). Action, project and career are organized in a hierarchy and sequence within each of the systems and in a hierarchy among the systems. Action is defined by a short-term action goal identified at the top level of the action organization. The subordinated middle level of the action organization is identified as action steps, described in a functional way. The lowest level in the action organization consists of action elements addressed and measured in physical terms. Project is defined by a midterm project goal, at the top project organization level, project steps are understood as occupying the middle level of the project organization and project elements are located at the lowest level. Similar order is found in long-term career processes. 
Mostly, the family projects were the family of origin projects but in some other cases they were family of procreation projects.

Some young patients indicated that school is a source of stress and despair and, if the situation at home is also stressful it might be difficult to recuperate and, following a hurtful experience, a suicide action could be committed.

A patient, (ID Nr 15) a young female about 20, described stress at school which left her with no resilience at home (no positive experiences at present) prior to her suicide:

'When I walked to the cupboard with pills I was thinking about my life. I have stress at school. I even don't know what I want to become. Everything turned negative. It gave me the push to this action (to commit suicide). In such a moment one is searching for reasons in order to justify such an action. One excuses oneself in such a moment.'

The patient identified her boyfriend who deserted her to come back again as the immediate reason for her distress. She recalled several near rapes as the source for her emotional sensitivity and described her parental ongoing care project in which her coping with these issues is embedded.

Stress at school or unfulfilled expectation of the parents could lead to parental intervention, which could cause a deep distress in the patient.

A patient (ID $\mathrm{Nr} 5$ ), a 17year old young girl, described how she was hindered by her mother to regularly visit her new boyfriend in another town because of her low grades at school. The patient's mother operated with unrealistic expectations, which the patient recognized as such and felt hopeless. Thus, the family educational and vocational project clearly played a dominant role and was colliding with the relationship project. Her boyfriend was not supportive and did not show any understanding for her situation and was not prepared to continue in developing their relationship under such circumstances. As the issue of relationship was a traumatizing experience for the patient, the patient felt desperate and performed a nonlethal suicide action:

'When I came home from work on Monday my mother said that we have to talk. She mentioned my grades in French - the last one was the lowest possible - and she wanted to forbid everything - using telephone, traveling to $\mathrm{Z}$ (a large city one hour by train) to see my boyfriend until I obtained the best possible mark in French. It occurred to me as being impossible to get the best mark in such a short time. This made me upset that she said I could go to $\mathrm{Z}$ only after receiving the best grade and even then, only once a month. I called my boyfriend and told him everything. He said that once a month is a bit too seldom for a relationship.' (Soon after that the patient overdosed.)

Sometimes the choice of school or training may be found unsatisfactory, the patient is unhappy in her present life but also is not sure about the proposed new direction in vocational training and, being caught in such a trap, and also seeing that she loses a relationship she found important, the patient decides to commit suicide.

Patient (ID Nr 8), a young girl in her teens, studied nursing but would like to do something else. The suggested 'stable hand' training is not fully convincing. She indicated that the reason for her suicide was her job. This vocational choice insecurity was intertwined with the relationship to a couple of 'horse' people:

Physician: 'What would you say if someone asked you for an open and honest reason for your attempting suicide?'

Patient: 'I would say that it was because of my work...

I studied nursing. Then I did not do well anymore and I interrupted the studies in February. I would have been able to continue in September. I spent the whole Summer deciding whether or not I should do it. I was persuaded by others that I should start again. I knew all along that I don't want to. But I was unable to say so. When I went back to the hospital on Monday it all started again. I've realized that I don't want to do that. I swallowed the pills in the evening and decided to give up my life.'

The patient also talked about her parents being pleased that she returned to the nursing profession she did not like indicating that their family project related to patient's occupation was a conflictuous one.

In another case the ambitious education goal proved to be too strenuous to work for. 
Then she decided to change the school (university admission studies instead of business school) and is currently on holiday. Obviously, her life crisis is a part of her vocational seeking process as well:

Consequently, the patient responded with a series of physical complaints and performed a non-lethal suicide action.

Patient ID Nr 10 described his problems with education (he is 24 years, in the second year of a 4-year university admission studies):

'I have been studying for one and half years. Beforehand, I passed some exams during the apprenticeship. And before that I made a final exam at the Polytechnic as engineering designer. Nine months before that I became allergic and had some problems with my wisdom teeth. This led to additional pain and tension in my back. I did not know where these pains were coming from. The last three years were torture.'

The patient also mentions his parents complaining that they are not going to pay for his private education forever while he stays in bed with illnesses no physician can identify. In fact, such an argument immediately preceded the patient's overdosing indicating how closely the occupational project, the suicide project and the family relationship project in this case were.

It also occurs that a person is happy with her occupational choice but after being asked to look for another job because failing her exams decides to commit suicide.

A patient (ID Nr 23), in her teens failed her exams in the school of her apprenticeship and was unable to continue in the old job:

'I did it on purpose (the suicide action). I was told on Friday that I had not passed the exam, though I was fully convinced that I am going to manage it. The following Monday I was not able to go to work as my boss told me a half a year ago that I would become redundant should I fail the exams. So, I thought about what to do so that I don't have to go to work. I went to the swimming pool on Sunday and planned that I am going to drown in that pool.'

Talking about her parents it becomes obvious that a complicated family relationship project is going on under which they all suffer: Therapist: You said that the other two sisters have (drug) problems. How do your parents manage to cope with this?

Patient: Not at all. Mother goes out late in the evening and gets drunk but only after my younger sister also began using drugs because my mother does not know how to help. And my father... I don't know why they didn't do anything. I've told my mother hundred times she should do something but she said I shouldn't get involved that's her business. Therapist: So, you mother declined your help

Patient: Yes

Therapist: And your father?

Patient: I don't talk ... already as a child I was afraid of him. I don't know why. But I did not talk to him. When I was small, I never went to ask him anything. I was always alone. I don't talk to him now either, because I would have to forgive him in order to talk to him.

Therapist: You are afraid of your father, why? Did he do anything particular?

Patient: No no. He was an alcoholic but is not any more. He does not drink any more. Perhaps we were afraid when he came home drunk. Therapist: What happened when he came home evenings?

Patient: I don't know. I can't say exactly. But I know ... there is an

image showing how mean he was which I kept in my mind. He has beaten up my mother for no reason. She was bleeding from her nose afterwards. He locked us in the rooms so that we would not see anything. I saw how much she suffered. She also tried to kill herself taking an overdose of pills and alcohol. She was then hospitalized but we were not allowed to visit her, as we were not to know what had happened.

In other cases, the revision of the occupational choice as present in a change of schools is only mentioned as a backdrop for other lifethreatening issues, but would, however, surely require some further exploration and thinking.

Patient (ID Nr 35), a young woman in her twenties, who studied at business school, experienced crisis, eating problems, depression, dropped all hobbies and reduced her life to only studying.
'I put myself under too much pressure. I went to a business school. I had semester exams. I studied day and night but I failed the exams... I decided then to study for exams after the summer holidays.'

'I was alone in my bed in the evening. I called my boyfriend. I could not go any further. Everything was over for me at that moment. Then I tried to cut my veins. But it did not work well. I was bleeding heavily but the vein was not cut through. I had the last semester exam the next day...'

Nevertheless, she also described a family relationship project, which she experienced as detrimental to her mental health. After the divorce of her parents she spent a year with her mother, who often punished her physically, left her alone for extended periods of time and used her as her friend to whom she complained a lot. The patient, 12 years old at that time, suffered tremendously and developed eating disorder:

'The main problem was my mother'

'I was twelve then. My mother made me feel guilty for everything. She also very often hit me hard with a belt. This was the main reason for my action'.

In some cases, the young patients reported that they were unhappy in their job, which then made them less resilient to other private problems such as to partnership problems.

Patient (ID Nr 24), in her early twenties, was unhappy in her job, but also once experienced a good boss in a different job who understood her:

'Then I've found a job in a drugstore. But I do not feel well there. I don't feel integrated in the team. I am unhappy when I have to go there in the morning. People who shop are always in stress and hurry. They want to be the first at the cashier. They don't care about other people. It is the same with the employees. Those are the best who leave as the first in the evening. That makes me upset. I don't get on with these people and my bosses.

It was Sunday when I took the pills ...but it (my work) hits me emotionally. Coming home on Saturday one is deadly tired. One takes a shower but one is not looking forward to anything. One is not motivated to start anything. Everything is too much.'

The patient also described her family relationship project in which she suffered a lot:

Patient: 'I have problems with my parents. I had problems mainly with my father. He is very indifferent. When I've told him anything, I had the feeling that he did not care.'

'My brother, he is the youngest, was adored by my mother. I was always jealous.

The jealousy consumed me nearly. I had the feeling that he was preferred.

My father was only talking to him, occasionally to my mother. He never talked to me. Mother was very pleased that he was interested in the same things as she was. She thought that he was the best.

I was inhibited to talk to my parents about what worries me. I was afraid.'

Other patients specified their unhappiness in the working place as being rooted in regular mobbing for no reason.

A patient (ID Nr 12), in her early twenties, described problems at work where she felt mobbed as a background for her feeling in stress and not being resistant:

'It started in summer when I began working in a new job... They terrorized me there. I was able to laugh at it at the beginning but it started consuming me. And three weeks ago, my boyfriend left me. Then he came back later saying that he loves me and that he stays. He repeated that - leaving me and coming back - several times. It was a 'there-and-back' between building-up and destroying hopes. There was a point when I had to say that I couldn't go on like this anymore, that it is too much for me. I came home frustrated from work and my boyfriend was there which made it worse.' (They started arguing and patient overdosed). 
Then I went to the bathroom and cut my veins. 'Work could be challenging not only in being too demanding but also under demanding. A patient, 35 years old, (Patient IDNr 16), described how she did not have much to do and thought about her problems during the night shift, which made her depressive. Thinking about her what she called 'wasted life' provided a trigger for her suicide action.

'Also, the work became too much for me. I am working at the post office and doing night shifts. I get problems in the night. I start thinking about why do I exist. I often do that. Perhaps it is because I have too much time to think. Sometimes there's a lot of work to do, but if you have things done, you can be bored. Everything is so monotonous.

The patient also indicated that the family relationship project was not much of help

Patient: '... she (her mother) doesn't show any feelings. She doesn't care what happens to me. It's the same as with my brother. She had never helped my brother when he was a drug addict, never. When he died, she paid the coffin and now she looks after the grave. Probably this will be the same with me. There she's going to pay; therefore, she's going to spend money. But one day I'm going to tell her, that this will cost a lot. My parents are divorced. I've seen how they had beaten each other. I then had to move to my grandmother. My brother was two years old when they had separated.'

Work could not only be challenging but also the life style of some colleague workers could be too facilitative in bad habits such as alcoholism.

A patient, (IDNr 28), male in early fifties, mentioned his previous working place of 13 years where he participated in intensive drinking:

'I always worked. One had a drink sometimes in the morning but sometimes I also drank some tea. I was really drinking a lot there. I shouldn't have gone there. I was there for too long, for 13 years, in the rain and snow, being badly paid.'

Sometimes the work is reported as being damaging to a partnership

The patient, (Patient IDNr. 37), a female around forty, reported that the working hours of her boyfriend and hers were different, they did not see each other much. Because of the relationship crisis she did not have enough energy to do her work and was dependent on social security benefits. Her son dropped out from his work. Thus, her work was the facilitator of her crisis but also suffered under that crisis.

'I am self-employed. I have two adolescent sons. I was divorced 11 years ago. I had a friend during the last 11 years. It worked fine. Suddenly he said he couldn't go on like this any longer. We had some crises, mainly because our working times were very different. He works weekends and evenings and myself during the day on working days. I have some problems with the older son. He has been depressive for some times. He is in treatment by a psychologist. He doesn't know what he wants. He lost all his self-esteem. As I invest lot of time into my son my boyfriend had the feeling that I am giving him too little attention.

Despite of her long independent life from her family of origin she reported a strong detrimental influence of the family projects she still felt a part of:

Patient: 'My father is an impossible person.... He threatened us that he is going to kill himself. Already as small children... We suffered a lot because of that. But he has never tried it.

He threatened that he is going to shoot, hang himself. It did not stop. We children were very confused. He is an egoist. He thinks only about himself, never about anybody else. Yes, he has a difficult life because of the illnesses. He hasn't been working for a long time. He had his leg amputated, has difficulties with his joints, has diabetes and has to go three times a week for dialysis. My sister suffers even more because of him. She married just to get away from home.

My parents are very demanding and want me to do taxi services for them and to look after them which I can't do because I have my work and my family. I also have another 4 siblings who could help as well.'

In another case the person worked such long hours that there was not much time left to take care of the family and to look after his wife's needs. 
A patient (Patient IDNr. 39), a male in his twenties used to work long hours and suffered then under his wife being unfaithful; he was asked by a colleague to work in his firm in D. but as he was not offered a higher position than his current one this offer was not really a solution. It was not a new start. He attempted suicide.

When I say that I'll be home at $4 \mathrm{pm}$ then I was home at $4 \mathrm{pm}$ and not at $8 \mathrm{pm}$ as usual when I even used to take some work home. But during this week I did not get anything in return. On that day (patient's suicide action) I did not get anything back either. In the evening a colleague rang to ask whether I am going to work for him or not. I arrived at the point when I had to say, there is nothing coming from my wife, I do have a family, a child whom I love more than anything else in the world. I have an excellent job and I am in demand. I've achieved everything so that I can go. I was so destroyed that I said I am not needed at this world. I pumped 270 units of insulin into my body that night.

This patient, a married man with a child, did not refer to any family of origin projects. However, when his wife realized that he was committing suicide she tried to reach her husband's family, parents and his brother, feeling helpless on her own. It was his brother who was able to take him to the hospital and save his life. Thus, the family project was very quickly actualized thought there previously was not much contact:

Patient: (while he was pumping insulin into his body) 'She (his wife) called my brother. He drove straight to T. During this time, I was able to pump further. My wife did not know what to do. She was frightened. She repeatedly called my brother on the cellular phone asking when is he going to come. She also tried to reach my parents and my sister... She did not know what to do... She was in panic... Occasionally, I lost consciousness. Then my brother came and

smacked my face.

Then he said that we have to talk. He was then talking for a half an hour and I was slipping into unconsciousness. Then he said that I should drink sugar water. I also took some 20 cubes of sugar with me. He wanted to take me to my parents, but I said that there is not enough time and that he should drive me to the hospital. Then I lost consciousness.

Often the overload is due to various engagements of the patients leading to negligence of the partner and home duties.

A patient (IDNr 29), a farmer and an active musician in his mid- sixties, was pressed to do some substantial renovation work in the house and suffered under too much work pressure. After drinking with his colleague musicians, he attempted a suicide.

It (relationship with his wife) became difficult. We wanted to renovate our kitchen, the attic, the corn had to be harvested... (the patient is animal farmer and also plays an instrument in a professional group with which he travels a lot). I came home Friday night and then half an hour later I did it (suicide action). I was completely overstressed... It was too much for me. We don't have financial problems, on the contrarily.

The patient, being in his sixties focuses at his family of procreation projects, which are in the very centre of his suicide. As the work could get intertwined with personal life, the subsequent changes could lead to the patient's overload which in return could be detrimental to his personal life and patient's well-being.

A patient (IDNr. 40), a young male in his early thirties, described changing a job, ending his relationship, starting a new relationship and working abroad. This all was new, it was too much work for him, he was stressed, and his new girlfriend wanted to terminate their relationship. The patient remembered the time when his parents divorced when he was 14 , his mother had to work and he felt lonely.

My former girlfriend left for two months for Australia and during this time I met at work a younger female colleague with whom I worked on some projects... A month later we became a couple... Another month later my former girlfriend returned to our shared flat and thought that our relationship will continue. Beforehand I applied for a new post, which involved lot of traveling.
So, I moved out of the flat, went abroad and when I came back for a weekend, I was busy with my colleagues, still in the middle of moving, in a new job and somehow, I realized that the relationship to my new girlfriend had changed. We were arguing on the phone and when I came back, she said that it does not work for her like this and that I have a problem with which she can't help me. It was too much for me... Everything broke down for me; I lost my hold... I was unable to sleep... In the morning I thought I couldn't go on like this, I don't want to... I sat down wrote down a couple of thoughts ... A farewell letter ... and went to the forest with a gun...

The patient also offered a narrative about a family project, which impacted him in the way, how he learned to deal with relationship in a detrimental way.

Patient: 'I told him (the patient's physician) that these thoughts date from my adolescence. They go back to where I was 14 and my parents divorced. I had been left alone. I didn't have any close relationships. I lived with my mother, but she always had to work. My school achievements had deteriorated. I got an apprenticeship because of a friend of my mother. That gave me a little support, but somehow, I've always been alone and had to fight for myself. That's why I clang to people, who meant a lot to me, as in the case of the girl. Also, the girlfriend with whom I was together for 8 years told me afterwards that she wanted to escape from my clinging. Again, in the following relationship with the other girl I

constricted her with my fears.

The work does not have to be the primary source of pressure and worries. However, once under the influence of other problems, such as health, the following difficulties could become a heavy burden for the patient. If unemployment results, this also is a stress some patients cannot cope with.

A patient (ID Nr 25), a male in his late fifties, reported that he could not work as a business traveler and was lost without his daily work.

I was unable to concentrate I had coughing fits and lost consciousness.

That's how I caused an accident. I've deposited my driving license and can't work at the moment because I am a travelling salesman. I would like to work as the roof is falling on my head. My girlfriend says that I am a burden for her because I don't work. Actually, I don't know anything else but work. It is crazy for me. I was never ill. It is hard time for me. He also indicated that the family relationship project is quickly deteriorating.

However, work could also be seen as an organizing principle and a facilitating frame for a relationship. Because of that, it could become a lifesaving feature.

A patient (IDNr 33), a female in her mid-forties, describing her working life mentioned that her friend picks her up every morning, which saved her life. Patient indicated that she became an astrologist, in order to understand her problems such as her alcohol consumption (pathological intoxication), losing control, getting hurt easily.

My boyfriend found me. He occasionally drives me to work. He rung but I did not reply. That was the reason why he came to check on me. (Patient overdosed around midnight the night before.)

The patient identified her alcohol problem as a part of a family relationship project

Patient: 'Perhaps I am showing similar behavioural patterns as my father. There are parallels in alcoholism though I don't know whether he also did not remember what he said the night before.

My father came always late after he spent some time drinking. There often was an argument but my mother said that one doesn't have to listen to that. One should not pay any attention to what he said. He was able to object, blame and complain for hours.

The work relevant knowledge could prove as being suicide facilitating. The following patient indicated that her work in a medical environment provides her with the necessary knowledge of an effective overdosing.

A patient (IDNr. 30), a woman in her forties, works in a medical firm and, therefore, knows how much medication it takes to kill her. She always had a fulltime job, felt content at work, worked a lot but admitted that her work and relationship were not balanced. She did not live an active, but only a contemplative relationship, seeking cosiness. Once her husband decided to leave her, her life lost any meaning for her. 
More than half of the patients disclosed how relevant they consider the work or occupational issues for their suicide without being asked about it and in nearly all narratives the family projects could be followed.

The patients presented a very complicated relationship between occupation and their suicide, which is even more complex when the embedding of them both in various interpersonal relations is considered. Consequently, although we did not specify the type of systemic order, we see behind these interrelationships we assume that these would be more informative than a probability calculation between various occupational issues and suicide processes.

As it is not very helpful for counsellors to reduce the relationship between occupational issues and suicide to facilitative or inhibitive, it is neither meaningful if we treat it in such a way. The 'self' or 'identity' related actions, projects and careers are visible, parent-child relationships seem relevant, partnership is quoted, addiction career is mentioned, occupational becoming a target issue, issues of retirement, processes of female empowering, sexual issues, unemployment, difficulties in managing semi-professional hobbies, the work and the demands of the partner at the same time and, finally, the suicide related actions, projects and career were described. Many of these issues are covered in family projects. Thus, the relationship between the occupational issues and suicide processes are embedded and intertwined with a series of other goal-directed processes which also need attention in dealing together with the client with the occupational issues and suicide or life related processes. These illustrations are not presented to show, that occupation is an important part in everyone's life and is thus involved somehow in patients' suicide action. Our aim is to indicate the necessity of considering the contextual nature of suicide as well as of occupational issues which cannot be reduced to the issue of content which can be easily separated in counselling or in therapy encounters suggesting that occupational issues are topics dealt with by a counsellor and suicide issues are dealt with by a psychotherapist. Of particular importance is the role of family projects. We were able to show, that the narratives of many patients after a non- lethal suicide action also contain descriptions of family projects as relevant in the patients' occupational career and in their suicide actions and projects. We indicate that this system order of goal-directed processes needs integrated attention and treatment.

\section{Shortcomings and limitations}

As this is an illustrative study based on interviews with patients after a nonlethal suicidal action, neither a full representativity nor great explanatory power can be claimed. The presented quotations are kept in their original form for readability purposes and are not quoted as content analysis categories, which might have better identified their place in the described goal-directed systems. Thus, the suggested coexistence of the two systems, the occupational and the suicide related issues as well as their reference to family projects are not indicated in conceptual terms. Further, as we did not explore the occupational issue in the interviews we cannot, therefore, maintain that the rest - nearly $50 \%$ - of the other suicide patients did not experience their occupational careers and projects as a part of their suicide career and projects. If asked, the patients might have reported about their occupational life in an equally intensive manner. They might have also elaborated more on their thoughts about the connection between their occupational life and their suicide actions and projects. The presented information should be seen as a part of the offered suicide narrative in a setting facilitating first of all suicide relevant narratives.

\section{Conclusion}

1) Elsewhere we suggested the heuristic value of seeing occupational and career related issues in terms of goal-directed systems of actions, projects and career. We provided a methodology and empirical material from a longitudinal and prospective study to support these claims (Valach, Young, \& Lynam, 2002; Young, Domene, \& Valach, 2015; Young, Valach, \& Collin, 2002).

2) In a series of publications based on empirical research projects we outlined the positions that suicide processes though destructive and often chaotic could be seen in terms of goal-directed systems in form of actions, projects and careers. 
This conceptualization allows the therapist to join these processes and support the life-related goal-directed processes, and help in making the switch to the suicide processes less urgent (Michel \& Valach, 2002, Valach, Michel, Young, \& Dey, 2002; Valach \& Young, 2015).

3 ) In this presentation we showed that the suicide related goal-directed systems and the occupation related goal-directed processes are well interwoven and that the occupation related processes are often a part of the suicide related processes.

4) We were able to indicate that while in some patients their suicide career, projects and actions were facilitated by their problems in occupational career, projects and actions, in other patients the interlinking of these two goal-directed systems brought an inhibiting influence into the suicide system and thus in some cases even saved the life of the patients. This aspect needs more attention as the occupational goal-directed system can function as a life related career and projects. We in particular underlined the role of as family projects which often provided either the backdrop for the intertwined suicide and occupational life goal-directed processes or are even the core of the present suicidal crisis.

5) We suggest that suicide prevention cannot live from hindering suicide processes but must also be active in facilitating life related processes. Addressing the occupational issues would help the medical professionals, psychiatrists and psychotherapists, psychologists and social workers strengthen their working base and increase their impact. Equally important is the suggestion that career counsellors should obtain qualifications in identifying suicidality and include this issue into their work. Being able to identify family project would help both professions. Also considering occupational projects and careers as a part of the life maintaining projects and career might provide the occupational counsellors with the necessary awareness of the seriousness of their work.

6) We propose that neither unemployment nor engaging in suicidal career should exclusively be dealt with within the 'disengagement ' institutions, be it an unemployment office or the medical system as a close contact to the occupation related goal-directed processes, on the one hand, and the life related goal-directed processes, on the other, is essential.

\section{References}

1. Domene, J. F., Valach, L., \& Young, R. A. (2015). Action in counselling: A contextual action perspective. In R. A. Young, J. F. Domene, \& L. Valach, (Eds.), Counseling and action. Toward life-enhancing work, relationship, and identity (pp. 151-166). New York: Springer.

2. Michel, K., Dey, P., Stadler, K., \& Valach, L. (2004). Therapist sensitivity towards emotional life-career issues and the working alliance with suicide attempters. Archives of Suicide Research, 8, 203-213.

3. Michel. K. \& Valach, L. (2002). Suicide as goal-directed action. In Ed. K. van Heeringen (Ed.), Understanding Suicidal Behaviour: The Suicidal Process Approach to Research and Treatment (pp 230-254). Chichester: Wiley \& Sons.

4. Richardson, M. S. (2002). A metaperspective for counseling practice. Journal of Vocational Behavior, 61, 407-423.

5. Richardson, M. S. (1993). Work in people's lives: A new location for counseling psychology. Journal of Counseling Psychology, 40, 425-433.

6. Savickas, M. L. (2005). The theory and practice of career construction. In S. D. Brown \& R. W. Lent (Eds.), Career development and counseling: Putting theory and research to work (pp. 42-70). Hoboken, NJ: John Wiley \& Sons.
7. Valach, L., Michel, K., Young, R. A., \& Dey, P. (2002). Attempted suicide stories: suicide career, suicide project, and suicide action. In L. Valach, R. A. Young, \& M. J. Lynam (2002). Action theory. A primer for applied research in the social sciences (pp. 153-171). Westport, CT: Praeger.

8. Valach, L., \& Wald, J. (2002). Action theoretical perspective in rehabilitation. In L. Valach, R. A. Young, \& M. J. Lynam. (2002). Action theory. A primer for applied research in the social sciences (pp. 173-197). Westport, CT: Praeger.

9. Valach, L., \& Young, R. A. (2015). Suicide and counseling for suicidality. In R. A. Young, J. F. Domene, \& L. Valach, (Eds.), Counseling and action. Toward life-enhancing work, relationship, and identity (pp. 295-313). New York: Springer.

10. Valach, L., Young, R. A., \& Lynam, M. J. (2002). Action theory. A primer for applied research in the social sciences. Westport, CT: Praeger.

11. Valach, L., Young, R. A., \& Michel, K. (2004). Counselling for vocational career and life projects: Action conceptualization. In Swiss Association for Educational and Vocational Guidance SVB- ASOSP (Ed.), Quality development in vocational counseling and training. International conference 2003: Final report (CD). Berne: Author.

12. Whiston, S. C., \& Keller, B. K. (2004). The influence of the family of origin on career development: A review and analysis. The Counseling Psychologist, 32, 4, 493-568.

13. Young, R. A. (1984). Vocation as relationship. Counseling and Values, 28, 169-178.

14. Young, R. A., Ball, J., Valach, L., Turkel, H., \& Wong, Y. S. (2003). The family career development project in Chinese Canadian families. Journal of Vocational Behavior, 62, 287-304.

15. Young, R. A., \& Collin, A. (Eds.), (2000). The future of career. Cambridge: Cambridge University Press.

16. Young, R. A., Domene, J. F., \& Valach, L. (2015). Counseling and action. Toward life-enhancing work, relationship, and identity. New York: Springer.

17. Young, R. A., Marshall, S., Domene, J. F., Arato-Bolivar, J., Hayoun, R., et al. (2006). Relationships, communication, and career in the parent-adolescent projects of families with and without challenges. Journal of Vocational Behavior, 68, 1-23.

18. Young, R. A., \& Valach, L. (2004). The construction of career through goal-directed action. In R. A. Young \& A. Collin (Eds.), Social Constructivism and Career. Special Issue of the Journal of Vocational Behavior, 64, 3, 499-514.

19. Young, R. A., Valach, L., Ball, J., Paseluikho, M. A., Wong, Y. S., et al. (2001). Career development as a family project. Journal of Counseling Psychology, 48, 2, 190-202.

20. Young, R. A., Valach, L., \& Collin, A. (2002). A contextualist explanation of career. In D. Brown \& Associates, Career choice and development (4th ed., pp 206-252). San Francisco: Jossey-Bass.

21. Young, R. A., Valach, L., \& Domene, J. (2005). Qualitative ActionProject Methodology In B. E. Haverkamp, S. L. Morrow, \& J. G. Ponterotto (Eds.), Knowledge in Context: Qualitative Methods in Counseling Psychology Research, Journal of Counseling Psychology a special issue, 52, 2, 215-223.

22. Young, R. A. \& Valach, L. (2000). Reconceptualising career theory and research: an action-theoretical perspective. In R. A. Young, \& A. Collin (Eds.), The future of career (pp 181-196). Cambridge: Cambridge University Press. 